\title{
On the sensitivity of dimensional stability of high density polyethylene on heating rate
}

\author{
A. Zehtabeyazdi ${ }^{1}$, S. M. Zebarjad ${ }^{*}$, S. A. Sajjadi ${ }^{1}$, J. Abolfazli Esfahani ${ }^{2}$ \\ 1Department of Materials Engineering, Engineering Faculty, Ferdowsi University of Mashhad, Mashhad, Iran, \\ P. O. Box 91775-1111. \\ 2Department of Mechanical Engineering, Engineering Faculty, Ferdowsi University of Mashhad, Mashhad, Iran, \\ P. O. Box 91775-1111.
}

Received 27 November 2006; accepted in revised form 13 January 2007

\begin{abstract}
Although high density polyethylene (HDPE) is one of the most widely used industrial polymers, its application compared to its potential has been limited because of its low dimensional stability particularly at high temperature. Dilatometry test is considered as a method for examining thermal dimensional stability (TDS) of the material. In spite of the importance of simulation of TDS of HDPE during dilatometry test it has not been paid attention by other investigators. Thus the main goal of this research is concentrated on simulation of TDS of HDPE. Also it has been tried to validate the simulation results and practical experiments. For this purpose the standard dilatometry test was done on the HDPE specimens. Secant coefficient of linear thermal expansion was computed from the test. Then by considering boundary conditions and material properties, dilatometry test has been simulated at different heating rates and the thermal strain versus temperature was calculated. The results showed that the simulation results and practical experiments were very close together.
\end{abstract}

Keywords: thermal properties, simulation, dilatometry, HDPE, coefficient of linear thermal expansion

\section{Introduction}

High density polyethylene (HDPE) is the most widely used polyolefin polymers because of its moderate strength, low cost, excellent processability and high chemical resistance [1]. It can be used in many applications such as automotive, transportation, packing, petrochemical and oil industries. For example nowadays the use of HDPE pipes in petrochemical, oil and gas industries is very common [2]. Although HDPE parts are present in all industries its application has been constrained because of its low dimensional stability particularly at high temperature. Like other thermoplastic polymers it can not tolerate high temperature for a long time. According to literature there are two main methods to evaluate its tolerance at high temperature, the so called dimensional and thermal stability [3-7].

Dimensional stability of a material can be dictated by its coefficient of thermal expansion (CTE). There are two expressions of this quantity which first is volume $\left(\alpha_{v}\right)$ and the latter is linear $\left(\alpha_{L}\right)$ coefficient of thermal expansion. For isotropic materials $\alpha_{v}=3 \alpha_{L}$ approximately. Coefficient of linear thermal expansion (CLTE) is a material property that is indicative of material expansion upon heating. [8]. There are two familiar methods to determine CTE of the material. In fact the exact definition depends on the range of studied temperature. If it is achieved at a specific temperature it can be called true coefficient of thermal expansion or $\alpha_{t}$. But sometimes it is preferred to measure ther- 


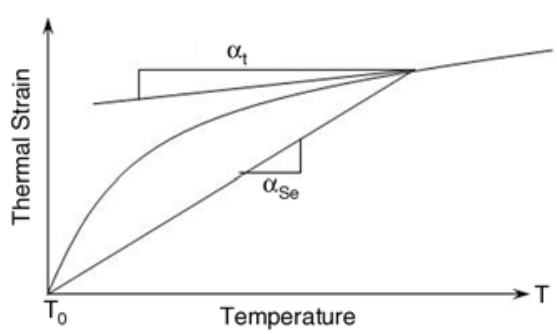

Figure 1. True and Secant coefficient of thermal expansion

mal expansion over a temperature range which is called secant coefficient of thermal expansion (SCTE) or $\alpha_{s e}$. The true coefficient is related to the slope of the length versus temperature, while the secant coefficient is determined by the slope of the chord between two points on the curve (Figure 1).

The magnitude of CTE based on true and secant can be obtained using Equation (1) and (2), respectively [9]:

$\alpha_{s e}=\frac{L-L_{0}}{L_{0}\left(T-T_{0}\right)}$

$\alpha_{t}=\frac{\mathrm{d} L}{L \mathrm{~d} T}$

where $L$ is the length at $T, T_{0}$ is the initial temperature $\left(25^{\circ} \mathrm{C}\right.$ in this work) and $L_{0}$ is the length at $T_{0}$ (zero thermal strain). Also, Thermal strain due to length change can be calculated using Equation (3):

$\varepsilon_{t h}=\alpha_{s e}\left(T-T_{0}\right)$

CTE can be calculated using both theoretical and experimental methods. There are many papers concentrating on the calculation of thermal expansion using theoretical methods [10-12]. For example Garai [11] found a correlation between heat capacity and volume coefficient of thermal expansion of highly symmetrical monatomic arrangements for some metals. Furthermore, thermal expansion coefficient of crystalline polymers has been predicted by Kardos et al. [10]. The approach was based on the assumption that a crystalline polymer can be descirbed as a multi-ply laminated composite. The results of their calculations showed a good agreement between theoretical and experimental data of an isotropic sheet of quenched HDPE.

Like theoretical methods there are many studies focused on CTE of polymers experimentally [1320]. The base of almost all papers was dependency of length change on temperature. Simha et al. [16] evaluated thermal expansivities at low temperature on a series of polymer blends over the whole range of composition from pure polyethylene to pure polypropylene. Brillhart et al. [17] studied the thermal expansion of a kind of polyamide using wideangle x-ray scattering (WAXS) method from $25^{\circ} \mathrm{C}$ to $325^{\circ} \mathrm{C}$. Jayanna and Subramanyam [18] examined thermal expansion of irradiated polyethylene from 10 to $340 \mathrm{~K}$ by using the three-terminal capacitance technique and it was found that the CTE was constant at radiation varies from 10 to $110 \mathrm{~K}$ and decreased as radiation increased up to $340 \mathrm{~K}$.

In spite of importance of heating rate on dimensional stability and SCTE of HDPE, there are a few papers concentrated on it. Therefore, in this paper it is tried to elucidate the role of both heating rate and temperature on dimensional stability and SCTE of HDPE. Also, it will be an attempt to simulate of system to clarify the dependency of SCTE on both heating rate and temperature.

\section{Experiments}

\subsection{Sample preparation}

In order to evaluate the thermal expansion behavior of HDPE, one of polymer by the trade name of Eltex B4020 from Solvay Polyolefins, Rosignano, (Italy) was used. The details of the used polymer are summarized in Table 1 . The samples were produced using an OIMA-85 ECO 3080 injection molding machine c/o Interplast, Scandicci (FI), Italy. The temperature was increased progressively along the apparatus from 160 up to $200^{\circ} \mathrm{C}$. Then the standard samples were performed by cutting the injected samples to get the final size of about $18 \times 4 \times 4 \mathrm{~mm}$. Since during cutting, the sample surfaces became a little bit rough thus just to reduce experimental errors the surface of all samples were polished by using wet grinding method. The polishing was continued to achieve a surface roughness of about 10 micron. It is worth noting to avoid increasing temperature the polishing was done under cooling water system.

Table 1. Specification of used HDPE

\begin{tabular}{|c|c|c|c|}
\hline $\begin{array}{c}\text { Melting } \\
\text { Temperature } \\
{\left[{ }^{\circ} \mathbf{C}\right]}\end{array}$ & $\begin{array}{c}\text { Crystallization } \\
\text { Temperature } \\
{\left[{ }^{\circ} \mathbf{C}\right]}\end{array}$ & $\begin{array}{c}\text { Crystallinity } \\
\text { Index }\end{array}$ & Grade \\
\hline 129 & 117 & $56 \%$ & Injection \\
\hline
\end{tabular}




\subsection{Dilatometry test}

Dilatometery test is the simplest way to predict dimensional stability of materials [9]. The dilatometry apparatus was Dima_85ECO3080. The machine was equipped with cooling circulation system. To find out the role of heating rate on change in length, the samples were heated from room temperature up to $70^{\circ} \mathrm{C}$ at different heating rates i.e. $2,5,10,20,30,40$ and $60^{\circ} \mathrm{C} / \mathrm{min}$. The change in length corresponding to each temperature was measured directly. Three samples for each material were tested. All samples were taken away after reaching to room temperature. Then SCTE and thermal strain were calculated for each heating rate by Equation (1) and (3), respectively.

\subsection{Simulation}

The main goal of using simulation method was to predict the sensitivity of dimensional stability of HDPE on heating rate. To do so the following objects were investigated.

- Effect of heating rate on temperature gradient.

- Effect of heating rate on strain gradients.

- Variation of displacements and thermal strains versus temperature using experimental data.

The used thermo physical properties are shown in Table 2. In the current study SCTE was taken into account as a function of 1) Temperature and 2) both temperature and hearting rate. It is worth noting that the originality of the current study is paying attention to both temperature and heating rate, simultaneously. Furthermore, dependency of SCTE on temperature gradient was neglected because of low temperature gradient.

Simulation was done using finite element method. Just for getting the most stable results the different element divisions were tried. The optimum results were obtained using the following divisions.

Length $(X$ direction $)=$ Height $(Y$ direction $)=5$ elements and width $(Z$ direction $)=20$ elements. Hence the used total elements are 500 elements. Initial and boundary conditions were applied on the

Table 2. Thermo-physical properties of HDPE as a function of temperature

\begin{tabular}{|l|c|c|c|c|}
\hline \multicolumn{1}{|c|}{$\mathbf{T}\left[{ }^{\circ} \mathbf{C}\right]$} & $\mathbf{0}$ & $\mathbf{5 0}$ & $\mathbf{1 0 0}$ & $\mathbf{1 5 0}$ \\
\hline $\mathrm{K}\left[\mathrm{W} / \mathrm{m}^{2}{ }^{\circ} \mathrm{C}\right]$ & 0.44 & 0.38 & 0.32 & 0.25 \\
\hline $\mathrm{C}_{\mathrm{P}}\left[\mathrm{J} / \mathrm{kg}^{\circ} \mathrm{C}\right]$ & 1640 & 2050 & 2860 & - \\
\hline $\mathrm{E}[\mathrm{MPa}]$ & 2500 & 1350 & 350 & - \\
\hline$\rho\left[\mathrm{kg} / \mathrm{m}^{3}\right]$ & - & $940-960$ & - & - \\
\hline
\end{tabular}

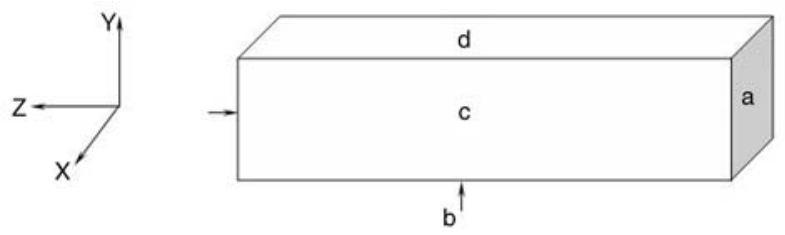

Figure 2. The applied boundary conditions on the surfaces. $a$ : Constrained in all directions, $b$ and $d$ : constrained in $Y$ direction, $c$ : constrained in $X$ direction

HDPE model according to the push rode dilatometry. The conditions are shown in Figure 2 schematically.

\section{Results and discussions}

Figure 3 illustrates variations of displacement of HDPE along Z-direction versus temperature. As it can be seen a raise in temperature corresponds to more displacement along $Z$-direction. The true reason of this variation can be attributed to boundary condition (applied to Figure 2) which can have an effect on chain vibration and free volume of HDPE. Displacement counters along $Z$-direction due to increasing temperature at the several heating rates are shown in Figure 4. As it shows the displacement is distributed uniformly along the specimen ( $\mathrm{Z}$ direction) except near the surface because of constraint.

Figure 5 shows that the latent thermal strain variation as element vanishes from origin point. This behavior is expected by considering the Equations (1) and (3). Also as seen in Figure 3 and Figure 5 both displacement and $\varepsilon_{\text {th }}$ along Z-direction raise as heating rate increase at a constant temperature.

To determine the temperature distribution within the specimen, the results of simulation of thermal analysis can be useful. The Results show that the

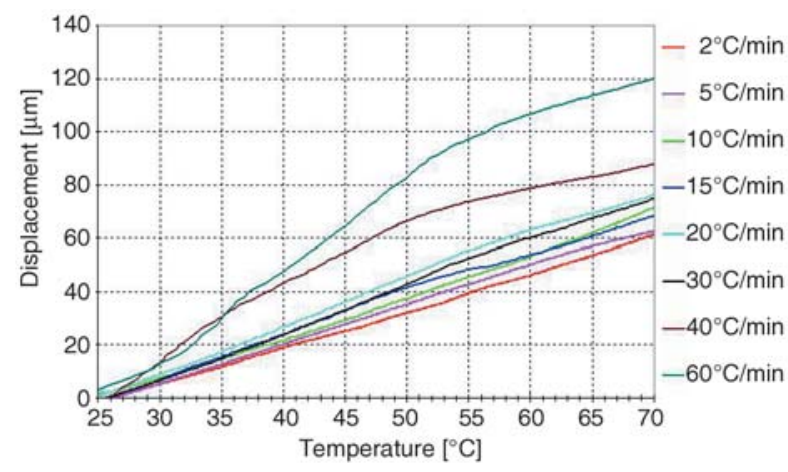

Figure 3. Experimental displacement versus temperature along $Z$ direction at different heating rates 

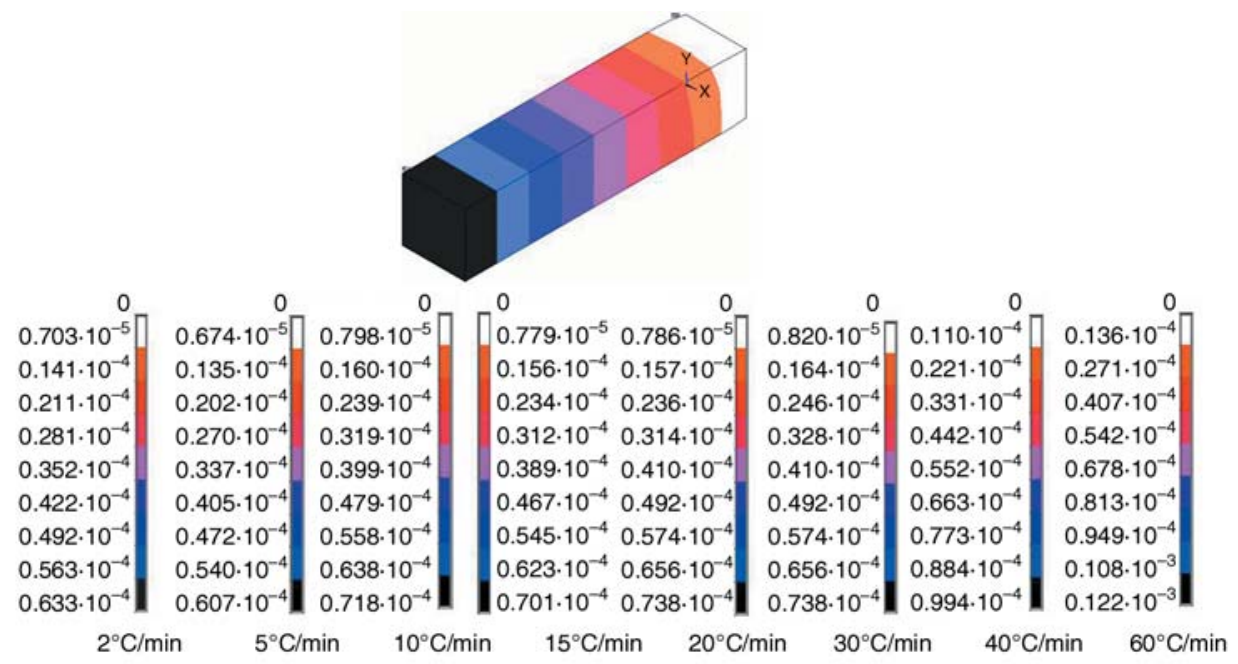

Figure 4. Displacement counters along $z$-direction due to increasing temperature at the several heating rates

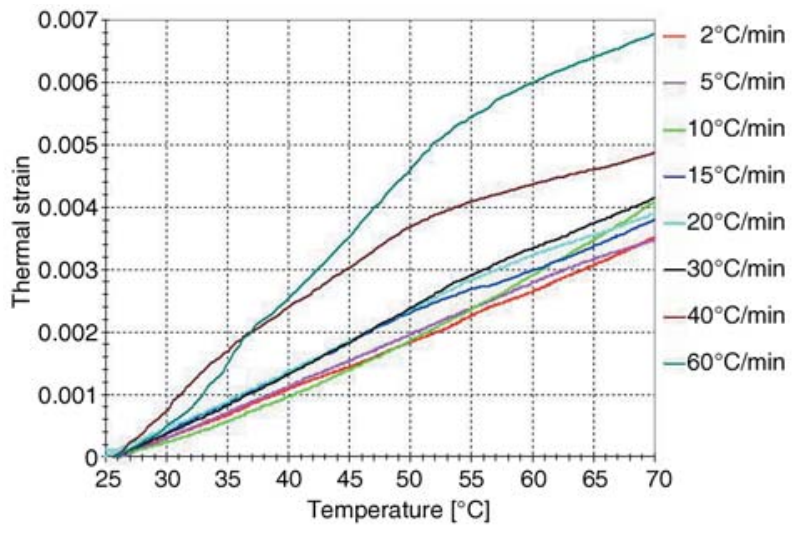

Figure 5. Experimental thermal strains versus temperature along $Z$ direction at different heating rates

maximum temperature gradient occurs at the heating rate of $60^{\circ} \mathrm{C} / \mathrm{min}$ and it is about $10 \%$ of final temperature approximately, since the sample size is very small. The temperature contours are shown in Figure 6. The result of numerical calculation of SCTE is shown in Figure 7. As it can be observed both thermal strain and SCTE show an increase as temperature increases. At each heating rate, two separated regions can be recognized. At the beginning of test the slope is almost linear but gradually the slope shows a nonlinearity behavior. The reason of linear behavior at the beginning of each curve can be attributed to reaching the sample temperature to the considered temperature. After passing from linear part, nonlinearity behavior of SCTE as a function of both temperature and heating rate appears. Indeed SCTE of HDPE shows a different behavior at low and high temperatures and heating rates. Looking at in more details on Figure 7 shows that there is a critical heating rate i.e. $30^{\circ} \mathrm{C} / \mathrm{min}$ and

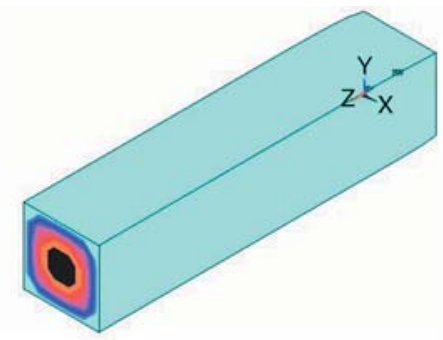

\begin{tabular}{|c|c|c|c|c|c|c|c|}
\hline 69.652 & 69.399 & 68.742 & 68.593 & 67.640 & 66.583 & 65.386 & 63.469 \\
\hline 69.678 & 69.464 & 68.874 & 68.749 & 67.897 & 66.963 & 65.886 & 64.194 \\
\hline 69.703 & 69.529 & 69.005 & 68.905 & 68.154 & 67.342 & 66.387 & 64.920 \\
\hline 69.728 & 69.595 & 69.136 & 69.061 & 68.412 & 67.722 & 66.887 & 65.646 \\
\hline 69.753 & 69.660 & 69.267 & 69.217 & 68.669 & 68.102 & 67.388 & 66.371 \\
\hline 69.779 & 69.725 & 69.398 & 69.373 & 68.926 & 68.481 & 67.888 & 67.097 \\
\hline 69.804 & 69.790 & 69.529 & 69.529 & 69.183 & 68.861 & 68.389 & 67.823 \\
\hline 69.829 & 69.856 & 69.661 & 69.685 & 69.441 & 69.241 & 68.889 & 68.549 \\
\hline 69.855 & 69.921 & 69.792 & 69.841 & 69.698 & 69.620 & 69.390 & 69.274 \\
\hline 69.880 & 69.986 & 69.923 & 69.997 & 69.955 & 70.000 & 69.890 & 70.000 \\
\hline
\end{tabular}

Figure 6. Temperature distribution counters of HDPE specimens at different heating rates 


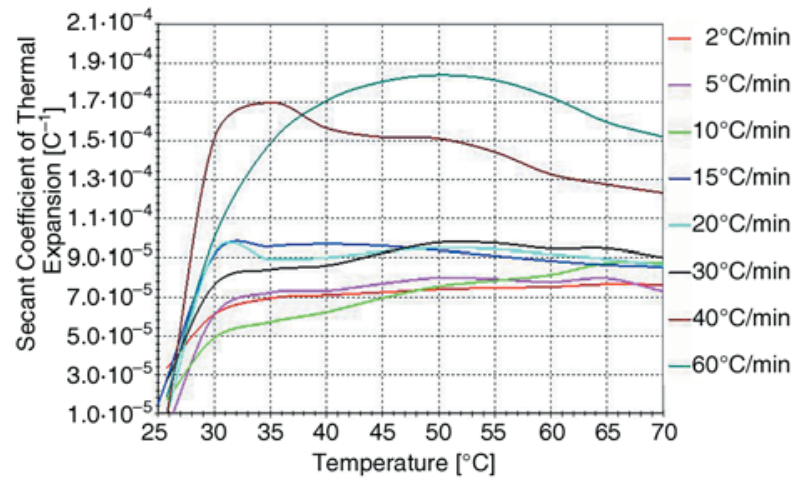

Figure 7. Experimental SCTE versus temperature along $Z$ direction at different heating rates

if heating rate becomes greater than the rate SCTE will be shown a nonlinearity behavior other wise it will be changed linearity as temperature increases. The subject should be under attention is post crystallization (recrystallization) of polyethylene during reheating. This is because polyethylene is a semi crystalline polymer and its spherulite size and even its crystallinity can be affected by heating and reheating. To clarify post crystallization looking at in more details on Figure 7 can be useful. The figure shows that at low heating rates (i.e. 2, 5, 10, 20 and $30^{\circ} \mathrm{C} / \mathrm{min}$ ) trends of the curves are smooth unlike high heating rate (i.e. 40 and $60^{\circ} \mathrm{C} / \mathrm{min}$ ). In fact at high heating rate the spherulites have not enough time to rearrange unlike at low heating rate. This behavior can be a result of more recrystallisation (or post crystallization) of polymer [21-22].

Our results differ from those presented by other investigators is that we take into account the effect of both temperature and heating rate on SCTE. While previous scientists have paid attention just to temperature, the effect of heating rate on SCTE has been neglected. For example, the result of an investigation which was concentrated on SCTE of crystalline polymeric solids showed a linear relationship between SCTE and temperature [13]. The authors believe that the reason of nonlinearity can be influenced by thermal shock and distribution of strain within the HDPE specimen.

Using simulation and computation of SCTE, thermal strains at different heating rate were calculated. The results of the thermal-structural analysis are shown in Figures 8 and 9. Figures 8a and 9a show the simulation results of SCTE as a function of just temperature. Dependency of SCTE on both temper-
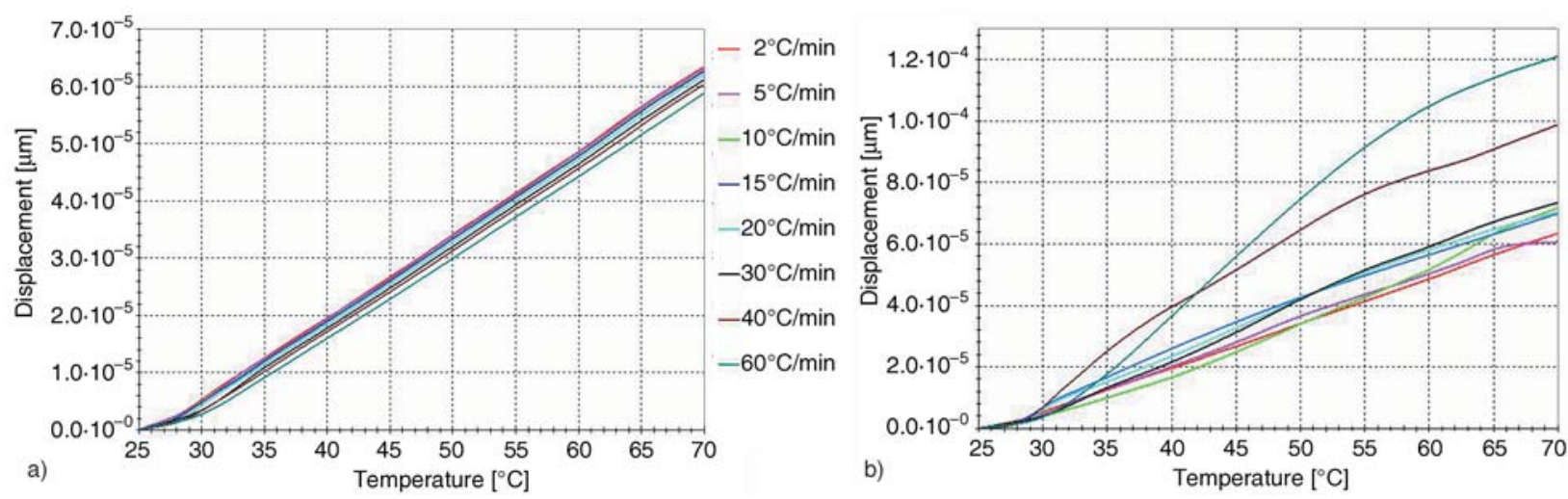

Figure 8. Simulated displacement versus temperature along $Z$ direction at different heating rates. a - SCTE is as a function of temperature. $\mathrm{b}$-SCTE is as a function of both temperature and heating rate
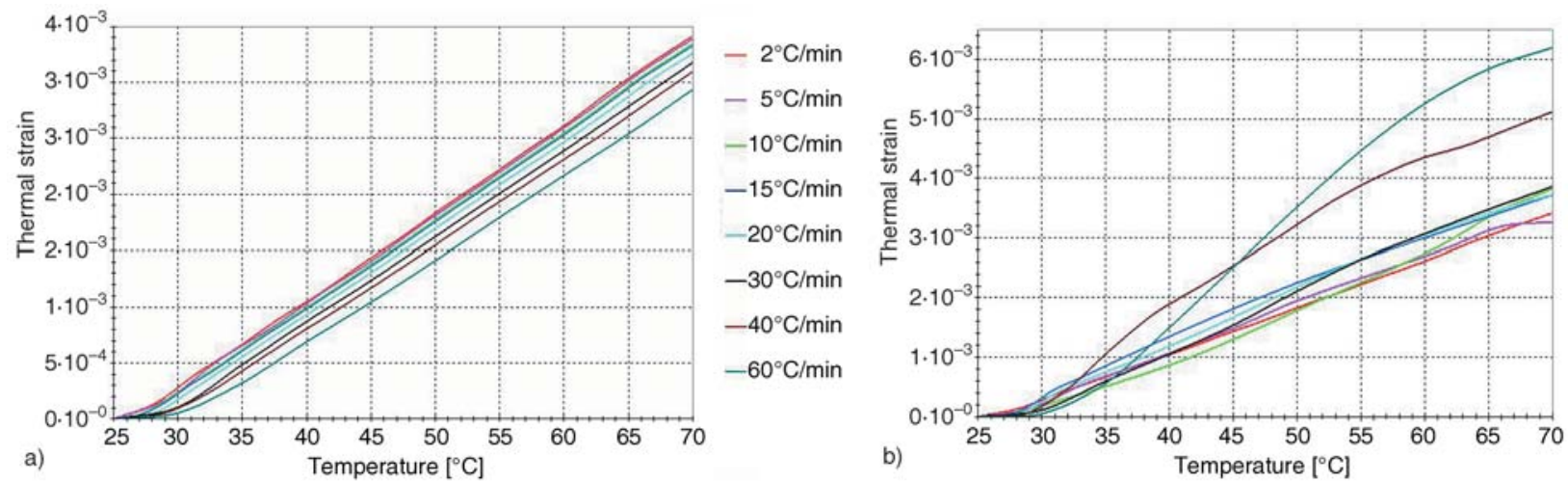

Figure 9. Simulated thermal strain versus temperature along $Z$ direction at different heating rates. a - SCTE is as a function of temperature. $b$ - SCTE is as a function of both temperature and heating rate 
ature and heating rate are illustrated in Figures $8 \mathrm{~b}$ and $9 \mathrm{~b}$. The simulation results show thermal strain is not in good agreement with experimental data when SCTE is just as a function of temperature while validity of simulation of thermal strain can be achieved if SCTE is as a function of both temperature and heating rate.

\section{Conclusions}

To investigate the sensitivity of dimensional stability of high density polyethylene on both temperature and heating rate the standard dilatometry test was done on the HDPE specimens. Secant coefficient of linear thermal expansion was computed from the test. Then by considering boundary conditions and material properties, dilatometry test has been simulated at different heating rates and the thermal strain versus temperature was calculated. The results are remarked as bellow.

- Both Thermal strain and SCTE depend on heating rate.

- There is a critical heating rate in which dependency of SCTE on both heating rate and temperature will be changed.

- The results of simulation show a good agreement with experimental data.

\section{References}

[1] Dong W. C., Kwang J. K., Byoung C. K.: Effects of silicalite-1 nanoparticles on rheological and physical properties of HDPE. Polymer, 47, 3609-3615 (2006).

[2] Rajendra K. K.: Analysis of ductile and brittle failures from creep rupture testing of high-density polyethylene (HDPE) pipes. Polymer, 46, 11664-11672 (2005).

[3] Walker C., Sigbritt K.: Assessment of thermal and thermo-oxidative stability of multiextruded recycled PP, HDPE and a blend thereof. Polymer Degradation and Stability, 78, 385-391 (2002).

[4] Seong O. H., Dong W. L., Oc H. H.: Thermal degradation of crosslinked high density polyethylene. Degradation and Stability, 63, 237-243 (1999).

[5] Bernal-Lara T. E., Liu R. Y. F., Hiltner A., Baer E.: Structure and thermal stability of polyethylene nanolayers. Polymer, 46, 3043-3055 (2005).

[6] Ulas I.: Drawing of high density polyethylene tube Effect of different cooling conditions. Polymer Engineering and Science, 39, 855-861 (1999).

[7] Bagdade S. D.: ASM Ready Reference: Thermal properties of metals. ASM International, Materials Park, Ohio (2002).
[8] ASTM E228-95. Standard test method for linear thermal expansion of solid materials with a vitreous silica dilatometer (1995).

[9] Zahran R. R., Shenouda S. S., El-Tawil Y. A., ElKayar A.: Analysis of the thermal expansion behavior of oriented polyoxymethylene sheets. Polymer Engineering and Science, 36, 1377-1386 (1996).

[10] Kardos J. L., Raisoni J., Piccarolo S., Halpin J. C.: Prediction and measurement of the thermal expansion coefficient of crystalline polymers. Society of Plastics Engineers, 19, 1000-1009 (1979).

[11] Garai J.: Correlation between thermal expansion and heat capacity. Computer Coupling of Phase Diagrams and Thermochemistry, 30, 354-356 (2006).

[12] El-Tonsy M. M.: Low cost technique for measuring thermal expansion of thin polymer samples. Polymer Testing, 22, 57-62 (2003).

[13] Thomas C. H., Sue A. B. A., Paul A. K.: In situ measurement of the thermal expansion behavior of benzocyclobutene films. Journal of Polymer Science Part B: Polymer Physics, 37, 311-321 (1999).

[14] ASTM E831-93: Standard test method for linear thermal expansion of solid materials by thermomechanical analysis (1993).

[15] ASTM D696-03: Standard test method for coefficient of linear thermal expansion of plastics between $-30^{\circ} \mathrm{C}$ and $30^{\circ} \mathrm{C}(2003)$.

[16] Zakin J. L., Simha R., Hershey H. C.: Low-temperature thermal expansivities of polyethylene, polypropylene, mixtures of polyethylene and polypropylene, and polystyrene. Journal of Applied Polymer Science, 10, 1455-1473 (1966).

[17] Brillhart M. V., Cebe P.: Thermal expansion of the crystal lattice of novel thermoplastic polyimides. Journal of Polymer Science Part B: Polymer Physics. 33, 927-936 (1995).

[18] Jayanna H. S., Subramanyam S. V.: Thermal expansion of irradiated polyethylene from 10 to $340 \mathrm{~K}$. Journal of Polymer Science Part B: Polymer Physics, 31, 1095-1098 (1993).

[19] Pottiger M. T., Coburn J. C., Edman J. R.: The effect of orientation on thermal expansion behavior in polyimide films. Journal of Polymer Science Part B: Polymer Physics, 32, 825-837 (1994).

[20] Broer D. J., Mol G. N.: Anisotropic thermal expansion of densely cross-linked oriented polymer networks. Polymer Engineering and Science, 31, 625-631 (1991).

[21] Wunderlich B.: Thermal Analysis of Polymeric Materials. Springer-Verlag, Berlin (2005).

[22] Zachmann H. G.: Schmelzerscheinungen und Kristallisationserscheinungen bei makromolekularen Substanzen. 6. Ergebnisse der Rontgenkleinuntersuchungen und Weitwinkeluntersuchungen an Polyglykolterephthalat (Terylen). Makromolekulare Chemie, 52, 23-28 (1962). 